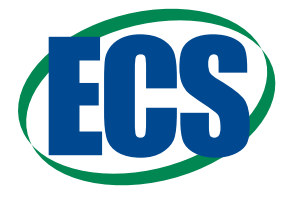

Focus Issue of Selected Papers from IMLB 2016 with Invited Papers Celebrating 25 Years of Lithium lon Batteries

\title{
Simulation and Measurement of the Current Density Distribution in Lithium-Ion Batteries by a Multi-Tab Cell Approach
}

\author{
S. V. Erhard, ${ }^{a, *, z}$ P. J. Osswald, ${ }^{a}$ P. Keil, ${ }^{a, *}$ E. Höffer, ${ }^{a}$ M. Haug, ${ }^{a}$ A. Noel, ${ }^{a}$ J. Wilhelm, ${ }^{a, *}$ \\ B. Rieger, ${ }^{\text {a,*}}{ }^{2}$ K. Schmidt, ${ }^{\text {a }}$ S. Kosch, ${ }^{\mathrm{a}, *}$ F. M. Kindermann, ${ }^{\mathrm{a}, *}$ F. Spingler, ${ }^{\mathrm{a}, *}$ H. Kloust, ${ }^{\mathrm{b}}$ \\ T. Thoennessen, ${ }^{\text {b }}$ A. Rheinfeld, ${ }^{\text {a } *}$ and A. Jossen ${ }^{\mathrm{a}}$
}

\author{
${ }^{a}$ Institute for Electrical Energy Storage Technology (EES), Technical University of Munich, Munich, Germany \\ ${ }^{b}$ Custom Cells Itzehoe GmbH, Itzehoe, Germany
}

\begin{abstract}
A single-layered NMC/graphite pouch cell is investigated by means of differential local potential measurements during various operation scenarios. 44 tabs in total allow for a highly resolved potential measurement along the electrodes whilst the single layer configuration guarantees the absence of superimposed thermal gradients. By applying a multi-dimensional model framework to this cell, the current density and SOC distribution are analyzed quantitatively. The study is performed for four $\mathrm{C}$-rates $(0.1 \mathrm{C}, 0.5 \mathrm{C}, 1 \mathrm{C}, 2 \mathrm{C})$ at three temperatures $\left(5^{\circ} \mathrm{C}, 25^{\circ} \mathrm{C}, 40^{\circ} \mathrm{C}\right)$. The maximum potential drop as well the corresponding SOC deviation are characterized. The results indicate that cell inhomogeneity is positively coupled to temperature, i.e. the lower the temperature, the more uniform the electrodes will be utilized.

(C) The Author(s) 2017. Published by ECS. This is an open access article distributed under the terms of the Creative Commons Attribution 4.0 License (CC BY, http://creativecommons.org/licenses/by/4.0/), which permits unrestricted reuse of the work in any medium, provided the original work is properly cited. [DOI: 10.1149/2.0551701jes] All rights reserved.

(cc) BY
\end{abstract}

Manuscript submitted September 28, 2016; revised manuscript received December 20, 2016. Published January 5, 2017. This was Paper 1227 presented at the Chicago, Illinois, Meeting of the IMLB, June 19-24, 2016. This paper is part of the Focus Issue of Selected Papers from IMLB 2016 with Invited Papers Celebrating 25 Years of Lithium Ion Batteries.

Within the past decades, demand for lithium-ion batteries in mobile applications has significantly increased. Due to their well proven performance as well as their stability in long-term usage, lithium-ion batteries became the technology of choice for electrochemical energy storage devices. ${ }^{1,2}$ Still, the specific energy density as well as cycle life are constantly being optimized by either commercializing new active materials, electrolytes and additives or by reducing the fraction of non-active parts within a battery. Often, this corresponds to thicker electrodes or larger form factors leading to capacities of up to $100 \mathrm{Ah}$ per cell. In these large format cells, severe gradients in current density and temperature distribution can occur along the electrode stack, ${ }^{3-9}$ which might provoke a performance loss during operation due to inhomogeneous utilization. Also non-properly adapted thermal conditioning can have a crucial impact on the performance of larger cells. $^{10-12}$

Modeling of internal distributions of potential and temperature along the electrodes is quite challenging, since even to calculate only a few cycles, a lot of computational resources are required for fully resolved models. In literature, there are many examples for spatially resolved multi-dimensional modeling approaches, $, 8,9,13-16$ which aim at representing the cell's internal behavior in terms of potential, current density, state of charge (SOC) and temperature distribution. Unfortunately, all of these examples lack a detailed, i.e. spatially resolved experimental validation, which is capable of tracking internal variables instead of measuring the surface temperature at a few spots and considering the overall battery's terminal voltage. Also, only a few examples of direct measurements of the internal current density distribution were published so far. Zhang et al. ${ }^{6,7}$ built a specific LFP/graphite prototype cell for this purpose. A segmented cathode was used for analyzing the current distribution during discharge at varying C-rates and temperatures. This setup allows for a precise monitoring of the current of each electrode element individually. Large deviations in SOC of up to several percent were identified during the process of discharge. However, it is not clear how the cell temperature influences these results as no data analysis is shown regarding this boundary condition. Klink et al. ${ }^{17}$ also built a lab-scale prototype cell, which was set up for analyzing the current density distribution through the electrode layer thickness instead along its width and height. In their

\footnotetext{
*Electrochemical Society Student Member.

${ }^{\mathrm{z}}$ E-mail: simon.erhard@tum.de
}

work they investigated the distribution of current during the formation process of a graphite electrode. A similar approach was chosen by $\mathrm{Ng}$ et al., ${ }^{18}$ who analyzed multiple working electrodes to show that even low current densities can cause severe gradients within the electrodes.

In order to gain further insights into the behavior of a commercial cylindrical cell, Osswald et al. ${ }^{3,5,19}$ modified a 26650 LFP/graphite cell in such way that any of the four tabs along a $1.7 \mathrm{~m}$ long electrode can be accessed separately, whilst still showing stable behavior for more than 200 cycles. It was shown that potential drops as large as $10 \mathrm{mV}$ occur applying a discharge current of $0.1 \mathrm{C}$ to the most extended tab configuration. Further, a multi-dimensional model for the modified cell was built and the local potential measurement method was proven to be applicable as a tool for current density analysis as well as model validation purposes. ${ }^{4}$ Minor deviations between simulation and measurement were assumed to be related to the use of approximated parameters for the cell's heat capacity and thermal conductivity and the implementation of a simplified LFP electrode representation assuming very low diffusivity for its phase change mechanism. Waldmann et al. ${ }^{20}$ extended this study by experimentally investigating different tab patterns and their effect on the temperature development between the cell center and its surface. In continuation of these efforts, we studied the current density distribution along NMC/graphite electrodes in large format batteries allowing for an enhanced spatial resolution as well as an improved distinction between thermal and electrochemical processes.

For that purpose, a specific prototype cell following a form factor of $500 \times 100 \mathrm{~mm}^{2}$ was designed, which contains state-of-the-art electrode materials and was assembled by means of manufacturing processes at high industrial standards. By monitoring 10 tab pairs at each edge of the single-layered NMC/graphite pouch cell, the quality and resolution in measuring local potentials ${ }^{5}$ is maximized. Such a multi-tab cell can be used as measurement setup and validation tool for spatially resolved models in order to study effects related to electrode configuration and tab patterns, ${ }^{6,20-23}$ local relaxation processes ${ }^{24,25}$ or local impedance effects. ${ }^{3}$ Due to the specific cell design, any thermal gradient along the electrode can be avoided and, therefore, the superimposed effect of temperature inhomogeneity on cell performance is eliminated. A general study on the current density distribution within that cell during discharge derived from measuring local potentials and their deviation at varying $\mathrm{C}$-rates and temperatures is presented here. In the second part of this work, we apply our multi-dimensional modeling framework ${ }^{4}$ to reproduce the measured data and investigate the 
Single-Layered Multi-Tab Cell
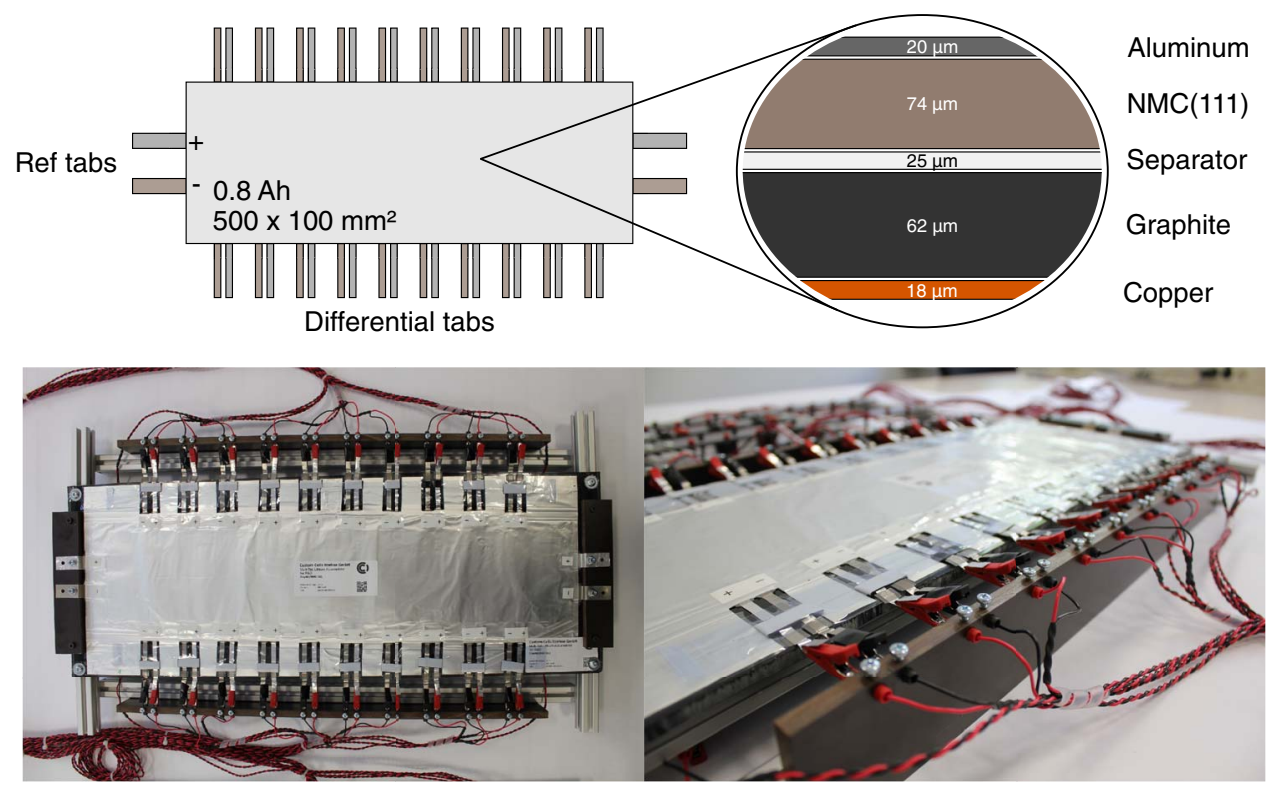

Figure 1. Schematic representation of the multi-tab cell configuration together with the dimensioning of the single-layered NMC/graphite electrode pair (top). The cell has a reference tab pair at the left and right side of the cell (Ref) and 10 pairs of positive and negative measurement tabs which are distributed equally on the top and bottom side of the cell. To assure mechanical stiffness, the cell is mounted on an acrylic back plate which is fixed to an aluminum frame. The reference tabs are connected by cable shoes which are screwed to the tabs whereas the potential measurement tabs are connected by alligator clips (bottom).

internal current density and SOC distribution theoretically depending on temperature and applied C-rate.

\section{Experimental}

Design considerations. - The cell is designed to analyze potential gradients within the current collector foils along a considerably long electrode in order to provoke a significant, i.e. detectable potential drop. As we are focusing on the cell's length, the width is kept rather small. The dimensions of the cell's current collectors are set to $500 \times$ $100 \mathrm{~mm}^{2}$. Even larger gradients can be provoked by longer electrodes, but in our case the size of the used climate chamber sets a restriction to that dimension. Thus, the cell length is a compromise of applicability and maximum signal amplitude. For further details of the cell configuration, see Fig. 1.

The cell comprises a $\mathrm{LiNi}_{0.33} \mathrm{Mn}_{0.33} \mathrm{Co}_{0.33} \mathrm{O}_{2}$ cathode and a graphite anode, as this material combination nowadays serves as a standard in many applications. The electrode loading is $2 \mathrm{mAh} \mathrm{cm}^{-2}$ for the NMC and $2.2 \mathrm{mAh} \mathrm{cm}^{-2}$ for the graphite electrode. That capacitive oversizing is assumed to help avoiding lithium plating during charging. Additionally, the anode is $2 \mathrm{~mm}$ larger in width and length than the cathode in order to suppress overvoltage peaks at the electrode edges. In total, the cell delivers about $920 \mathrm{mAh}$ at a $0.1 \mathrm{C}$ discharge. Its nominal capacity is rated as $0.8 \mathrm{Ah}$, thus the current at $1 \mathrm{C}$ rate is $0.8 \mathrm{~A}$.

The electrodes consist of single-sided coatings on current collector foil, which is aluminum on the cathode and copper on the anode side of the cell. Two larger tab pairs with $15 \mathrm{~mm}$ width are added at the smaller side of the cell and serve as reference tabs. By adding $10 \mathrm{tab}$ pairs along the electrode, voltage differences can be measured during operation of the cell. At every position, the positive as well as the negative current collector potential can be measured. For improved signal quality of that measurement, large tabs ( $5 \mathrm{~mm}$ width) were connected to the current collector foil by ultrasonic welding. Additionally, we performed a study on the distribution of the contact resistances and the ohmic contributions of the current collector by analyzing a non-coated foil with exactly the same tab pattern and materials.
Cell production.-The NMC $\left(111, \mathrm{LiNi}_{0.33} \mathrm{Mn}_{0.33} \mathrm{Co}_{0.33} \mathrm{O}_{2}\right)$ electrode consists of $86 \%$ active material (BASF), $6 \%$ PVdF-binder and $8 \%$ conductive additives. All percent values correspond to weight fractions. The cathode slurry was based on organic solvent and coated and dried by using a Mathis coating line. The graphite anode is made of $96 \%$ active material (Hitachi), $2 \%$ binder and $2 \%$ conductive additive. The anode slurry was based on water and coated and dried by using the same Mathis coating line. The electrolyte is $1 \mathrm{M} \mathrm{LiPF}_{6}$ in EC/DMC ( $1: 1$ by mass) plus $2 \% \mathrm{VC}$ as additive. The separator is a $\mathrm{PP}$ monolayer (Celgard 2500). At the shorter side of the cell $\mathrm{Al}$ and Ni plated $\mathrm{Cu}$ tabs (width: $15 \mathrm{~mm}$, thickness $0.2 \mathrm{~mm}$ ) and at the longer side $\mathrm{Al}$ and $\mathrm{Ni}$ tabs (width: $5 \mathrm{~mm}$, thickness $0.1 \mathrm{~mm}$ ) were connected by ultrasonic welding. The electrodes were packed in aluminum composite foil and dried in vacuum at an elevated temperature for $48 \mathrm{~h}$. The cell was filled with $10 \mathrm{ml}$ of electrolyte in an argon atmosphere. The formation process of the cell was carried out by running four cycles $(2 \times 0.1 \mathrm{C}, 0.2 \mathrm{C}, 1 \mathrm{C}$; charge: $\mathrm{CC} \& \mathrm{CV}$, discharge: $\mathrm{CC})$. Finally, the cell was charged to $3.7 \mathrm{~V}$ and degassed.

Coin cells for open-circuit voltage (OCV) measurement of NMC and graphite were produced by punching out small disks with a diameter of $14 \mathrm{~mm}$ from the same electrode sheets used for the multi-tab cell. The counter electrode used within the coin cells is a lithium metal foil with a thickness of $400 \mu \mathrm{m}$ and a diameter of $15 \mathrm{~mm}$. The coin cells contain the same electrode material, separator and electrolyte as the multi-tab cell and the same formation procedure was applied prior to operation. Four cells were built for each electrode. Half-cell potential measurements were performed at $25^{\circ} \mathrm{C}$ with a current rate of $0.02 \mathrm{C}$, while applying three cycles (after initial formation cycle). The mean value between the third charge and discharge cycle corresponds to the $\mathrm{OCV}$, taken as a reference for the model. Strictly speaking, averaging between a low rate discharge and charge cycle does not reflect the OCV of an electrode perfectly due to a remaining hysteresis as well as non-symmetric polarization. By application of very small currents (e.g. 0.02C), these impacts can be reduced to an acceptable level. In this case, we assume this technique to be sufficient for that type of analysis, since the main characteristics of the OCV are conserved, whereas the error is substantially small. Nevertheless, slight variations in precise positioning of graphite induced OCV changes 


\section{Table I. Multi-tab cell parameters.}

\begin{tabular}{lcc} 
Parameter & NMC & Graphite \\
\hline Number of single-coated layers & 1 & 1 \\
Electrode thickness $(\mu \mathrm{m})$ & 74 & 62 \\
Area specific capacity $\left(\mathrm{mAh} \mathrm{cm}^{-2}\right)$ & 2 & 2.2 \\
Porosity & 0.45 & 0.5 \\
Particle size D50 $(\mu \mathrm{m})$ & 12 & 22 \\
Width $(\mathrm{mm})$ & 98 & 100 \\
Length $(\mathrm{mm})$ & 498 & 500 \\
Separator type & \multicolumn{2}{c}{ Celgard 2500} \\
Separator thickness $(\mu \mathrm{m})$ & Aluminum & Copper \\
Current collector material & 20 & 18 \\
Current collector thickness $(\mu \mathrm{m})$ & 10 & 10 \\
Number of tab pairs & \multicolumn{2}{c}{}
\end{tabular}

might be assigned to this recording technique. Table I summarizes the cell parameters.

Measurement setup.-After formation, the cell is mounted onto its fixture and electrically contacted with alligator clips which are further connected to $2 \mathrm{~mm}$ banana sockets. At the reference tabs, cable shoes are connected in order to assure lower resistances for the terminal current. In this study, the cell current was only applied at one of the two reference tab pairs. In order to avoid any inhomogeneity due to non-symmetric operation over many cycles, the side was switched at the end of the measurements, while the contact resistance from the cable shoes as well as the electrical performance, capacity and cell voltage were monitored. No deviations were observed, so we assume a high reproducibility of the presented measurements, independent from the reference tab configuration.

In Fig. 2, the measurement setup is shown. A Basytec CTS is used for controlling current and voltage, while measuring the cell's voltage at the reference tab via two multi-channel voltmeters. A high precision analog data logger from Gantner Instruments records the voltage between the different tabs and the reference at one side of the cell. The resolution of the measurement systems increases for a smaller measurement range. Consequently, only differential voltages along the current collector instead of absolute cell voltages are measured. For comparison, an additional self-built data logger based on the ultralow noise 24-bit sigma-delta analog-digital converter (AD7193) by Analog Devices ${ }^{26}$ monitors the voltages at the other side of the cell. Following this procedure, 37 voltage signals are sampled simultaneously: one cell voltage signal at the reference tab, 8 voltage signals between the negative reference tab and each negative tab, 8 voltage signals between the positive reference tab and each positive tab on the right side. The same accounts for the other cell side. The sample rate of both data loggers is $2 \mathrm{~Hz}$. To monitor the signal quality, two differential measurement points, namely tab 4 and tab 7 , are replaced by an

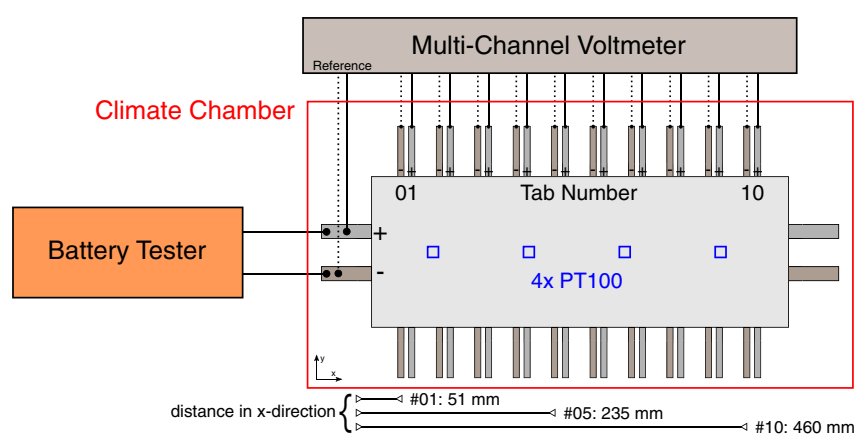

Figure 2. Measurement setup applied to multi-tab cell consisting of a battery tester, multi-channel voltmeters and four PT100s on its surface. The distance in $x$-direction between the reference tab and the tab of the negative current collector with number 01,05 and 10 is indicated. absolute voltage measurement between the current collector foils. Thus, these two differential voltages are not displayed in the plots.

Additionally, four equally distributed PT100 sensors are attached to the surface of the cell by means of Kapton tape which are monitored by the Gantner system. With this configuration, a temperature resolution of less than $0.1 \mathrm{~K}$ is achieved. Based on preliminary test results at $5^{\circ} \mathrm{C}$, the cell shows a temperature variation of less than $0.2 \mathrm{~K}$ at a $2 \mathrm{C}$ discharge rate with respect to its surroundings. For that reason, we conclude that no self-heating effect occurs at the investigated operation scenarios which would result in a considerable temperature increase. Hence, no temperature data is shown in the results section. This absence of transient and local temperature variations is one major advantage of a single-layered pouch cell design. This is due to the fact that the ratio of heat flux to the surrounding air is fairly large compared to the heat produced by the cell during operation. Consequently, this measurement setup allows for analyzing effects of large format electrodes without superimposing thermal gradients, as they would usually occur in a measurement setup based on commercial cells. ${ }^{10,21}$

The cell is exposed to discharge rates of $0.1 \mathrm{C}, 0.5 \mathrm{C}, 1 \mathrm{C}$ and $2 \mathrm{C}$ at temperatures of $5^{\circ} \mathrm{C}, 25^{\circ} \mathrm{C}$ and $40^{\circ} \mathrm{C}$. A VT4021 climate chamber (Vötsch, Germany) is used for controlling the temperature. Before any discharge operation, the cell is charged at a rate of $0.1 \mathrm{C}$ followed by a $\mathrm{CV}$ phase until the current drops below 0.01C. A relaxation period of $4 \mathrm{~h}$ is included between charging and discharging, ensuring enough time for compensation of any inhomogeneity. ${ }^{24}$

\section{Model Development}

We applied our multi-dimensional modeling framework ${ }^{4}$ to the cell described above. Since the cell is in quasi-isothermal conditions, no thermal model is considered here. The model represents the cell domain by considering 11 equally discretized elements for the corresponding tab pair region. This implies that 11 Newman-type ${ }^{27-29}$ models are coupled to a two-dimensional current collector domain, where the negative and positive current collector potentials are calculated. The basic idea behind the model coupling is the exchange of averaged values within a discretized element $A_{k}$. First, the potential is calculated within the current collector domain and transferred to the 11 Newman models. In the same time step, the resulting current density from the Newman model is fed back to the 2D model as source term. In Fig. 3 the modeling setup is shown containing the most important equations. For more details, the reader is referred to our previous work. ${ }^{4}$ The relevant model parameters are summarized in Table II. The geometry corresponds to the experimental cell domain, as shown in Fig. 1 and Fig. 2. During the measurement period the cell lost about $3 \%$ of its initial capacity. To compensate for that, the initial SOC is fitted accordingly. The model is solved in commercial finite-element method software Comsol Multiphysics 5.2a, which takes about 4 min for a $1 \mathrm{C}$ discharge with an i5 processor and 16 GB RAM.

\section{Results and Discussion}

Measured discharge profiles.-In Fig. 4 the cell voltage at the reference terminal (a) as well as the corresponding local potentials for the negative (b) and the positive current collector (c) are plotted as a function of discharged capacity during a $0.1 \mathrm{C}$ discharge at $25^{\circ} \mathrm{C}$. The cell voltage shows only the signal information restricted to the terminal (reference tabs), while the local potentials illustrate the potential distribution along the electrode. In preliminary tests we confirmed that the signals on both sides of the cell are identical. Thus, the potential is shown for only one side throughout the manuscript.

It can be seen that a differing current collector thickness and conductivity lead to corresponding amplitudes of the potential drop. The positive current collector foil faces the higher loss in potential due to its lower absolute conductivity. The factor of absolute potential drop in between both foils should be about

$$
\frac{\Delta U_{\text {neg }}}{\Delta U_{\text {pos }}}=\frac{20 \mu \mathrm{m} * 3.6 * 10^{7} * \mathrm{~S} \mathrm{~m}^{-1}}{18 \mu \mathrm{m} * 5.8 * 10^{7} * \mathrm{~S} \mathrm{~m}^{-1}}=0.69
$$



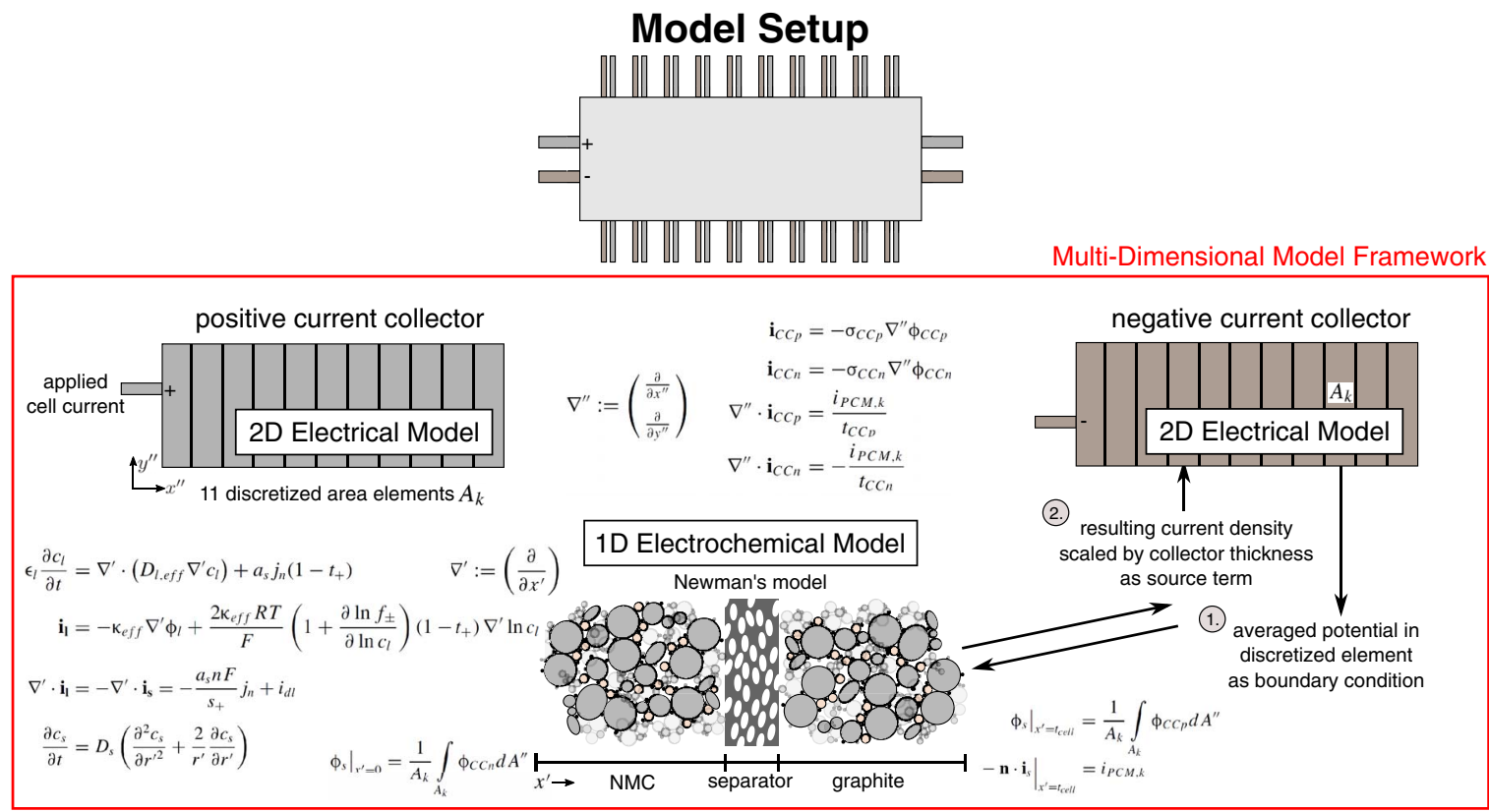

Figure 3. Model setup applied to the Multi-Tab Cell: Eleven 1D electrochemical models (based on Newman's work) are coupled to a 2D current collector domain by a potential-current exchange averaged within one element $A_{k}$. Only the main equations are shown, for more details the reader is referred to our previous publication. ${ }^{4}$

assuming common literature values for specific conductivities of copper and aluminum. ${ }^{30}$ Compared to the measured values in Figs. $4 \mathrm{~b}$ and $4 \mathrm{c}$, a ratio of about 0.5 can be seen in between the potential drop on the positive and negative current collector side, which confirms the assumed conductivity values. The deviation can be explained by the higher welding spot resistance at the reference tab in the positive current collector foil, yielding $1.4 \mathrm{~m} \Omega$ in contrast to $0.2 \mathrm{~m} \Omega$. The

\section{Table II. Model parameters.}

Parameter

NMC Separator Graphite

Open-circuit voltage

measured measured

Initial SOC

at $5^{\circ} \mathrm{C}$

at $25^{\circ} \mathrm{C}$

$0.40^{\mathrm{f}}$

$0.39^{\mathrm{f}}$

$0.41^{\mathrm{f}}$

at $40^{\circ} \mathrm{C}$

Theoretical max. concentration $\left(\mathrm{mol} \mathrm{m}^{-3}\right) \quad 51500^{\mathrm{a}}$

Active material volume fraction

$0.38^{\mathrm{a}}$

Solid state diffusivity $\left(\mathrm{m}^{2} \mathrm{~s}^{-1}\right)$

at $5^{\circ} \mathrm{C}$

at $25^{\circ} \mathrm{C}$

at $40^{\circ} \mathrm{C}$

$2.2 \mathrm{e}-14$

$3 e-14^{\mathrm{f}}$

$5 \mathrm{e}-14^{\mathrm{f}}$

$0.72^{\mathrm{f}}$

Reaction rate constant $\left(\mathrm{m} \mathrm{s}^{-1}\right)$

at $5^{\circ} \mathrm{C}$

at $25^{\circ} \mathrm{C}$

at $40^{\circ} \mathrm{C}$

Charge transfer coefficient

Electrolyte salt diffusivity $\left(\mathrm{m}^{2} \mathrm{~s}^{-1}\right)$

Electrolyte conductivity $\left(\mathrm{S} \mathrm{m}^{-1}\right)$

Electrolyte's activity dependence

Electrolyte's transference number

Tortuosity

Porosity

Current collector's conductivity $\left(\mathrm{S} \mathrm{m}^{-1}\right) \quad 3.6 \mathrm{e} 7^{30}$

Temperature dependency $\left(\mathrm{K}^{-1}\right)$

$$
\begin{gathered}
0.7 \mathrm{e}-11^{\mathrm{f}} \\
2 \mathrm{e}-11^{\mathrm{f}} \\
4 \mathrm{e}-11^{\mathrm{f}} \\
0.5^{\mathrm{a}}
\end{gathered}
$$

Fitted function ${ }^{3}$

Fitted function ${ }^{31}$

Fitted function ${ }^{31}$

$$
0.38^{31}
$$$$
3.5^{\mathrm{e}} \quad 2.5^{\mathrm{e}}
$$

$$
\begin{aligned}
& 2.5^{\mathrm{e}} \\
& 0.55^{\mathrm{e}}
\end{aligned}
$$

$0.004^{30}$

$5.8 \mathrm{e} 7^{30}$

$0.004^{30}$ signal peak positions along the width of the electrodes correspond exactly to each other for both current collectors (see Figs. 4b and $4 \mathrm{c})$. Looking into the spatial distribution of the electrode polarization along the ten tab positions, a characteristic quadratic potential curve can be observed, which shows the largest slope at the terminal tab and nearly no gradient at the opposite end of the cell. This implies that with increasing distance to the reference tab, the voltage drop between two tabs decreases. For example, the potential difference between tab 01 and tab 02 is larger than the potential difference between tab 09 and tab 10 (refer to Figs. 4b and 4c).

Furthermore, it can be seen that some voltage oscillations occur, as soon as an electrode region enters a state of charge with a corresponding OCV plateau, e.g. between 300 and 400 mAh (Figs. 4b and $4 \mathrm{c}$ ). Since the OCV of NMC shows nearly no variation from its

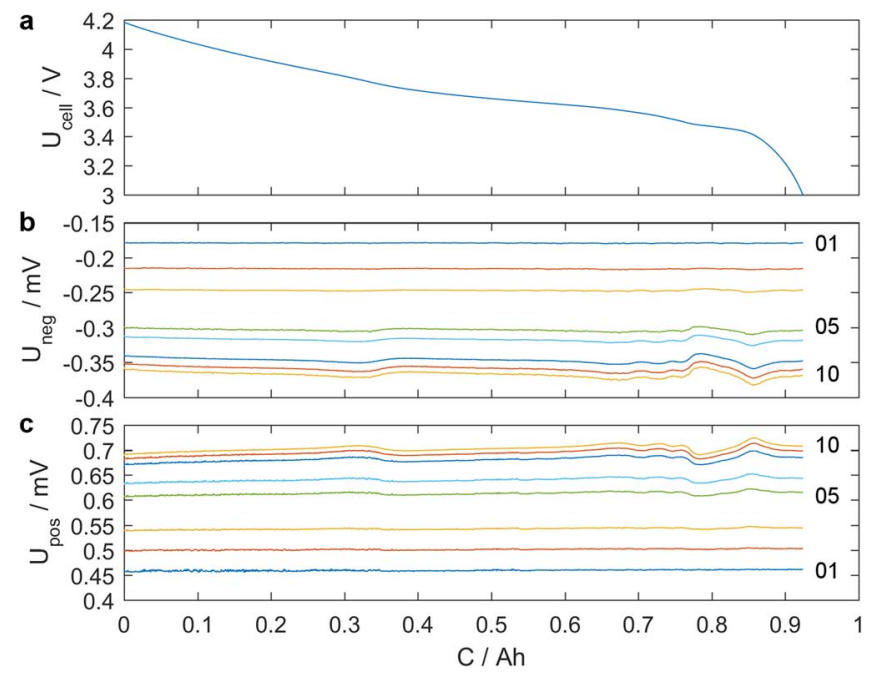

Figure 4. Discharge profile at $0.1 \mathrm{C}$ and $25^{\circ} \mathrm{C}$ measured at reference terminal (a) and corresponding eight differential potentials for the negative (b) and the positive current collector (c) plotted versus discharge capacity. Tab numbers are highlighted on the right side.

\footnotetext{
a assumed value.

estimated from Ref. 33.

${ }^{f}$ fitted value.
} 

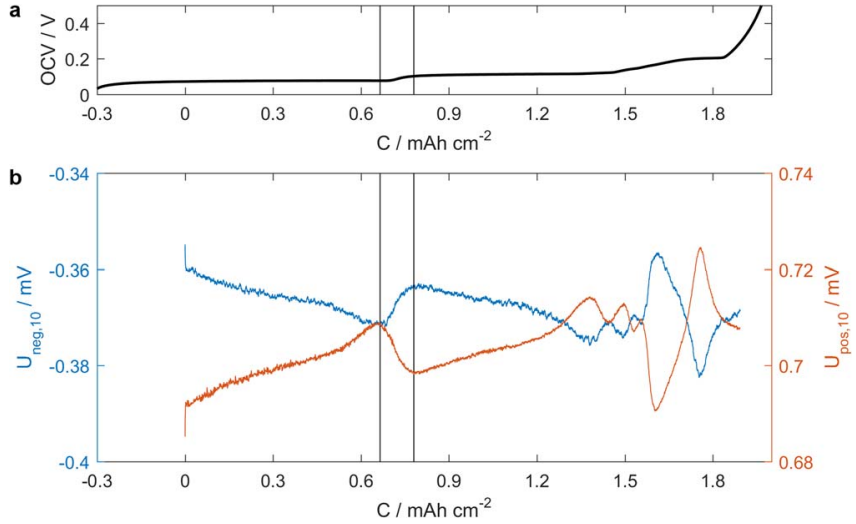

Figure 5. Half-cell potential of graphite (OCV) vs. lithium measured with the aid of coin cells at $0.02 \mathrm{C}$ and $25^{\circ} \mathrm{C}$ shifted by $14.7 \%$ due to the electrode balancing, plotted as a function of the specific capacity (a). Corresponding local potentials ( $U_{\text {neg, } 10}$ and $\left.U_{p o s, 10}\right)$ at tab \#10 of the negative and positive current collector, measured relative to reference tabs within the multi-tab cell during $0.1 \mathrm{C}$ discharge at $25^{\circ} \mathrm{C}$ (b). The vertical lines mark the region of the phase change within the graphite OCV.

monotonically decreasing behavior over a wide SOC range, the visible oscillations can be ascribed to the graphite's OCV steps between the plateaus. At about $350 \mathrm{mAh}$ the first characteristic voltage oscillations appear due to the change from stage 1 to stage 2 in the graphite electrode. Due to the overbalanced graphite electrode, this point is shifted to a higher SOC. It can be also observed that these oscillations are more pronounced with increasing distance to the reference tab, where the current is applied. Further, there is a slight increase in the overall slope of the differential voltage curves with increasing distance to the reference tab. This might be related to the relative polarization of the electrode section, which should be the lowest opposite the reference tab. In this region, the relative change due to an electrode OCV change is considerably large in comparison to the ohmic potential drop within the current collector, which results in a higher sensitivity to any variations in the electrode $\mathrm{OCV}$.

To further investigate the OCV influence, the graphite OCV (a) as well as the local potential measurement from the multi-tab cell (b) are shown in Fig. 5, plotted as a function of the specific capacity. The OCV curve in the upper part (a) corresponds to coin cell measurements at a $0.02 \mathrm{C}$ charge vs. $\mathrm{Li} / \mathrm{Li}^{+}$. The lower part (b) displays a $0.1 \mathrm{C}$ discharge of the multi-tab cell. Both measurements were performed at $25^{\circ} \mathrm{C}$. The OCV is shifted by $14.7 \%$ to the left in order to visualize the effect of slope changes on the local potential. Since the graphite is overbalanced by $10 \%$ and an irreversible capacity loss occurs during formation, $14.7 \%$ is a fairly realistic value. Obviously, the graphite OCV stages provoke the differential voltage oscillations along the current collector foil in the multi-tab cell. As soon as an electrode section closer to the reference tab enters a higher intercalation stage, the voltage difference to the next segment increases until that segment enters the same state of charge. Then, the voltage difference reduces to its initial value, which is mainly caused by an ohmic drop. Especially at lower lithiation degrees of graphite, more pronounced oscillations occur in the differential signal along the current collectors. The highlighted peak in the signal at about $0.65 \mathrm{mAh} \mathrm{cm}^{-2}$ can be clearly assigned to the phase transition from stage 1 to stage 2 in graphite. The features at a discharge capacity of about $1.3 \mathrm{mAh} \mathrm{cm}^{-2}$ reflect a more oscillating behavior due to more abrupt slope changes in the OCV and the absence of a significant plateau area. The OCV of NMC is not shown here as there are no distinct slope changes throughout the used lithiation range which would result in such an oscillating behavior.

Two major results can be concluded so far. At extended electrode length, the potential drop follows a more decreasing scheme during discharge being not only defined by the ohmic drop within the current collector foil. Slope changes within the active material's OCV cause

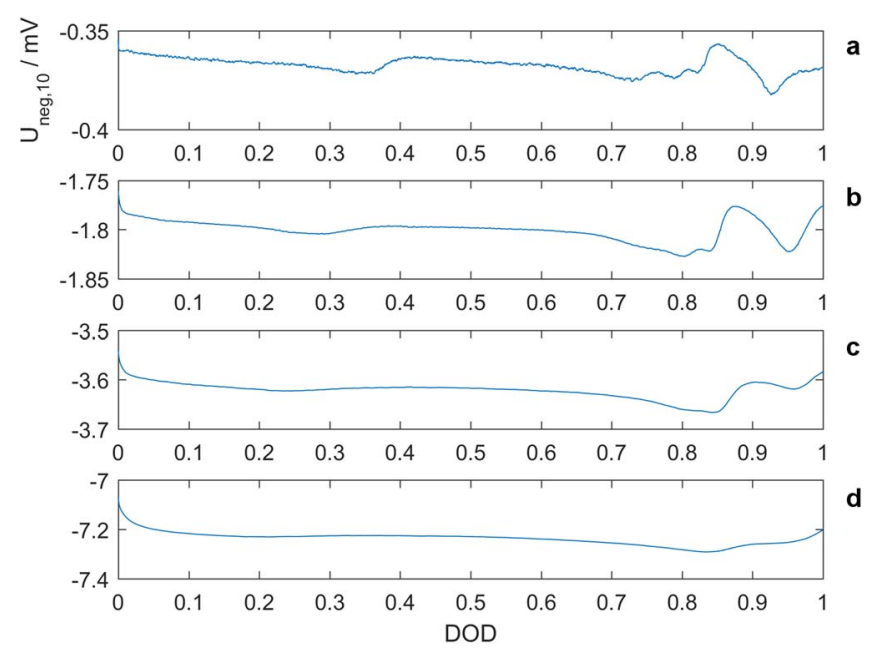

Figure 6. Rate dependency of the farthest local potential (tab \#10) at the negative current collector foil for $0.1 \mathrm{C}(\mathrm{a}), 0.5 \mathrm{C}(\mathrm{b}), 1 \mathrm{C}(\mathrm{c})$ and $2 \mathrm{C}(\mathrm{d})$ plotted versus DOD at $25^{\circ} \mathrm{C}$.

potential oscillations, being more pronounced at further distance to the reference terminal. When using NMC and graphite as electrodes, these oscillations can be related to the graphite's OCV curve. A maximum potential drop of about $0.7 \mathrm{mV}$ can be measured per $46 \mathrm{~cm}$ electrode length at a low rate of $0.1 \mathrm{C}$ in the positive current collector foil.

To study the rate dependency, Fig. 6 contains the signal from the farthermost tab \#10 for discharge current rates of $0.1 \mathrm{C}(\mathrm{a}), 0.5 \mathrm{C}(\mathrm{b}), 1 \mathrm{C}$ (c) and $2 \mathrm{C}$ (d) at $25^{\circ} \mathrm{C}$. In general, the ratio of potential drop within the current collector foils for differing C-rates corresponds well to Ohm's law. Moreover, the shape of the signal depends strongly on the current rate. In the first part of the discharge process, the slope at $2 \mathrm{C}$ (d) seems to be shaped smoothly in comparison to that at $0.1 \mathrm{C}$ (a). Further, the clear peak assigned to the graphite's phase transition is hardly visible at higher rates. We can assume that the higher potential drop along the current collector foil causes a less pronounced OCV influence and results in a flatter contour. This corresponds well to our investigation within modified commercial cells, ${ }^{5}$ where the same trend was observed. Especially at high DOD values of as large as $80 \%$ the potential drop characteristics change distinctly toward higher rates, which can be seen in a considerably flat profile at $2 \mathrm{C}$. In general, oscillations due to the OCV influence of graphite can be only identified at substantially low C-rates such as $0.1 \mathrm{C}$. Zhang et al. discussed this behavior and concluded that the OCV dependency is dominant over the potential drop along the current collector foil at lower C-rates. ${ }^{7}$ As soon as the rate is high enough, the ohmic drop determines the differential potentials to be more monotonically shaped. The order of magnitude of the potential loss is about $3.6 \mathrm{mV}$ per $46 \mathrm{~cm}$ negative current collector length for $1 \mathrm{C}$, resulting in a drop of approximately $0.08 \mathrm{mV}$ per $\mathrm{cm}$ electrode length. This might be important when designing cells with electrodes of up to meters in length in cylindrical configurations while adding only a few tabs due to manufacturing costs. This critically affects the active material utilization along the electrodes. For materials with very flat OCV such as LTO or LFP, this effect is even more pronounced, ${ }^{5-7,19}$ since larger gradients in current density occur due to the dominating potential drop along the electrodes.

Indication of SOC variations.-Differential voltage analysis (DVA) is performed for the local potential signals along the current collector and plotted for a $0.1 \mathrm{C}$ discharge at $25^{\circ} \mathrm{C}$ in Fig. 7 . In the upper part of the diagram (a), the overview of the entire DOD range is given. Main peaks can be seen at a DOD of about $37 \%$ and at DODs higher than $70 \%$. More detailed overviews of these DOD regions can be found in the lower part of the diagram (b and c). In contrast to (b), the curves (c) show a slight variation in the peak position of the 

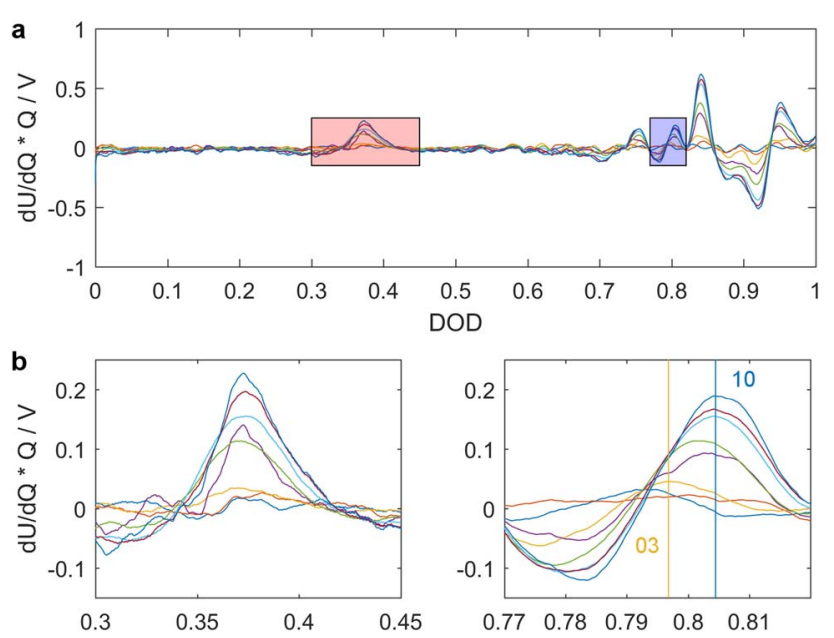

Figure 7. Differential voltage analysis of the local potential signals at a $0.1 \mathrm{C}$ discharge and $25^{\circ} \mathrm{C}$ (a) with two highlighted regions close to a DOD of $37 \%$ (b) and $80 \%$ (c). The line colors correspond to Fig. 4 and the maximum of tab position 03 and 10 is marked by a line.

corresponding tabs. In general, the peak shifts to larger DODs and is more pronounced with increasing distance to the reference tab. If we take a closer look to the $\mathrm{x}$-position of the local maximum in the DVA (refer to Fig. 7c), it turns out that the temporal DOD difference between tab 3 (yellow) and tab 10 (blue) is in the range of $0.5 \%$ to $1 \%$. This order of magnitude corresponds well to our recent investigation of a modified commercial cell, ${ }^{19}$ where we proposed about $1 \%$ to $2 \%$ SOC difference within a $128 \mathrm{~cm} \mathrm{LFP/graphite} \mathrm{electrode} \mathrm{segment} \mathrm{at}$ a $0.1 \mathrm{C}$ discharge at $25^{\circ} \mathrm{C}$. However, the signal quality is too low for a reliable quantitative analysis of DOD distribution, which relates to our measurement setup. Due to the limited size of the climate chamber, the data logger had to be placed outside. As a result, the signal quality suffers from the small differences in temperature fluctuation between inside and outside of the chamber, which are small in general, but when a sub- $\mu \mathrm{V}$ resolution is required, an inevitable noise occurs. Additionally, the relatively low control rate of the climate chamber and the accompanying temperature variations caused a negative effect on the preciseness of the voltage measurement setup and prevented a reliable DVA. For that reason, the setup was optimized by attaching a copper plate which is heated and cooled by two powerful Peltier elements, which yield an absolute temperature variation of less than $0.05 \mathrm{~K}$. Experimental work on this setup is ongoing. Here, we are restricted to state that at $0.1 \mathrm{C}$, deviations are visible, but can hardly be analyzed quantitatively. We can estimate the order of SOC deviation to be around $1 \%$ over a distance of approximately $26 \mathrm{~cm}$ (distance from tab 03 to tab 10) at a $0.1 \mathrm{C}$ discharge at $25^{\circ} \mathrm{C}$.

In comparison, the differential analysis at a $2 \mathrm{C}$ discharge and $25^{\circ} \mathrm{C}$ is shown in Fig. 8a. Throughout the entire DOD range nearly no characteristic peaks occur except at about $87 \%$. The peak is highlighted in the lower part of the figure (b). It can be seen that the point of intersection varies with the position along the electrode following the same scheme as for $0.1 \mathrm{C}$, the larger the distance, the later the intersection. So far, it can be stated that a SOC variation due to a peak shift within the DVA can be identified at a discharge at $0.1 \mathrm{C}$ as well as at $2 \mathrm{C}$. The intersections vary by about $0.5 \%$ to $1 \% \mathrm{DOD}$, comparable to the observations made at a $0.1 \mathrm{C}$ discharge. As stated before, these results are rather of a qualitative nature than a quantitative one. More generally, it can be stated that the artificially prolonged LFP/graphite cell shown in Ref. 5 is capable of showing higher SOC deviations, similarly identified by peak shifts of the DVA signal. This is due to the flat LFP voltage profile as well as the total distance between the measurement points of $128 \mathrm{~cm}$. To overcome this restriction related to the experiment for the multi-tab cell setup, our modeling framework was applied after validating it via the local potential measurement. Following this approach, we can give a more quantitative representation
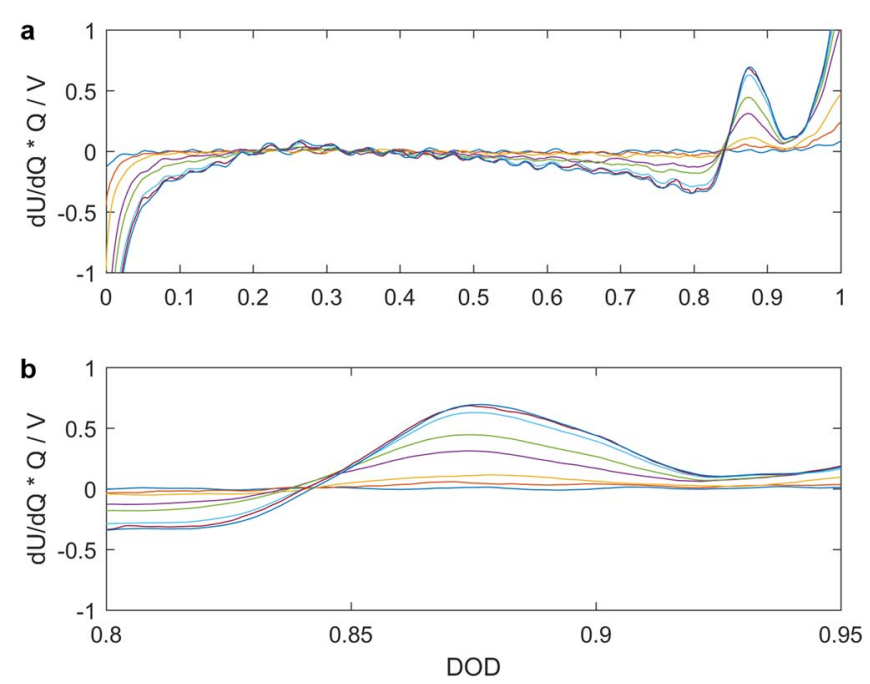

Figure 8. Differential voltage analysis of the local potential signal at $2 \mathrm{C}$ discharge and $25^{\circ} \mathrm{C}$ (a) with a highlighted region close to a DOD of $87 \%$ (b).

of the current density distribution within the cell in Model Analysis section.

Temperature dependency.-In Fig. 9, the temperature dependency of the local potential is presented for the farthest tab at three temperatures $\left(5^{\circ} \mathrm{C}, 25^{\circ} \mathrm{C}\right.$ and $\left.40^{\circ} \mathrm{C}\right)$ for a rate of $0.1 \mathrm{C}$ (a) and $2 \mathrm{C}$ (b). Here, the DOD is defined by the capacity of the cell at the corresponding temperature and discharge rate to allow for a reliable comparison. An increase in temperature causes the local potentials to oscillate more while showing a higher absolute potential drop along the current collector foil. At $0.1 \mathrm{C}$ and $5^{\circ} \mathrm{C}$, almost no peak or variation in the signal can be detected, which corresponds to a very homogeneous discharge procedure without any significant disturbances along the electrode. In contrast to that, the elevated temperature at $40^{\circ} \mathrm{C}$ emphasizes a peak between a DOD of $30 \%$ and $40 \%$ as well as several peaks after a DOD of $60 \%$ (Fig. 9a). The peak at about $90 \%$ discharge capacity is visible for all temperatures, but is much more pronounced at $40^{\circ} \mathrm{C}$. The difference between the absolute potential drops seems to have a linear correlation to the temperature difference between them. If we include an averaged linear temperature coefficient of $0.004 \mathrm{~K}^{-1}$ for
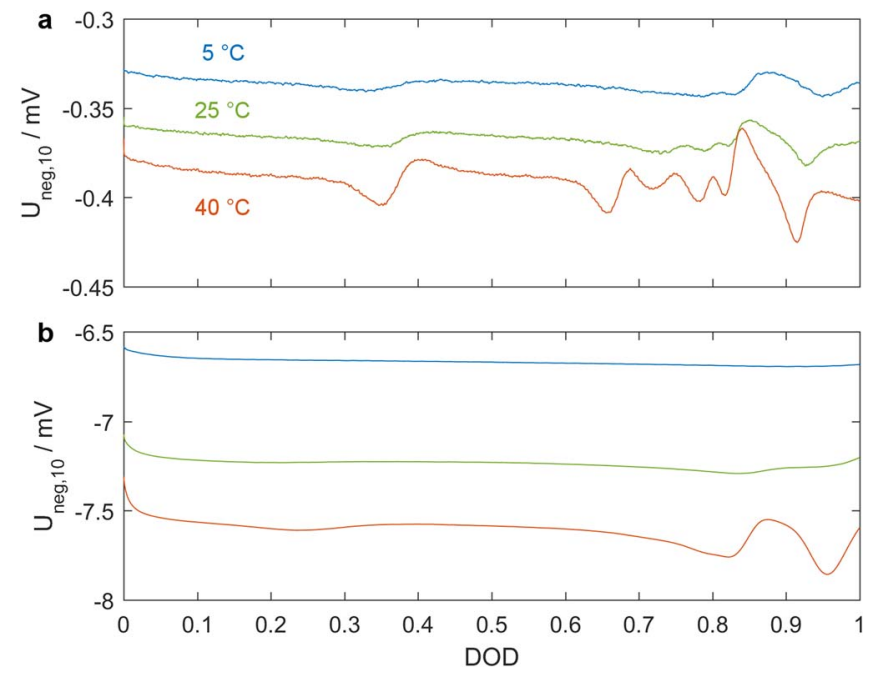

Figure 9. Temperature dependency of the local potential at the farthermost tab (\#10) within the negative current collector for three temperatures $\left(5^{\circ} \mathrm{C}\right.$, $25^{\circ} \mathrm{C}$ and $40^{\circ} \mathrm{C}$ ) at a $0.1 \mathrm{C}$ discharge (a) and a $2 \mathrm{C}$ discharge (b). 
$0.5 \mathrm{C}$
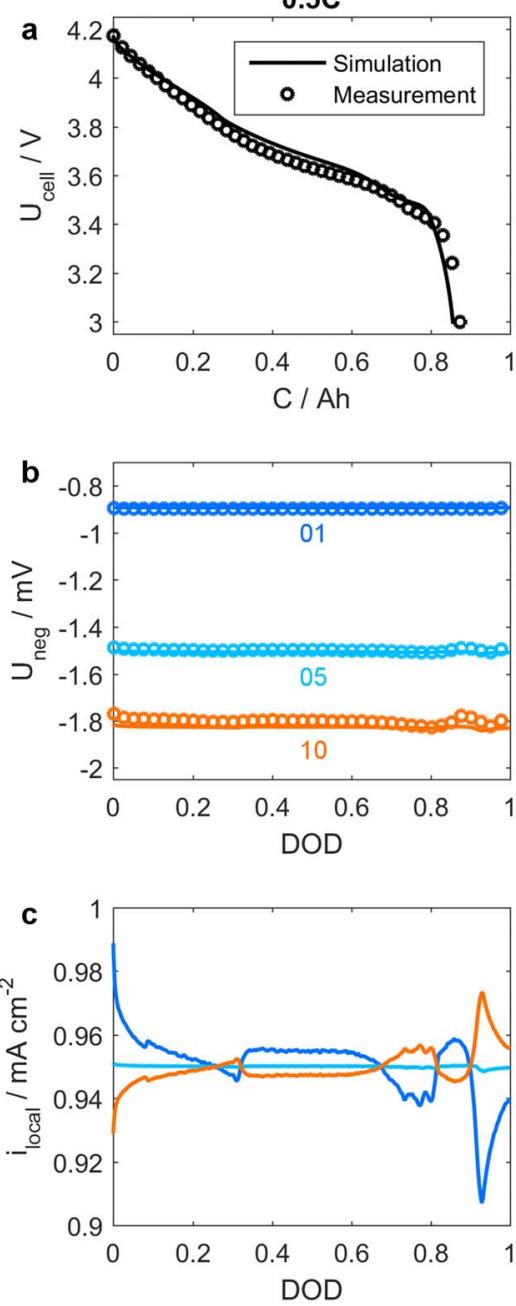

$1 \mathrm{C}$
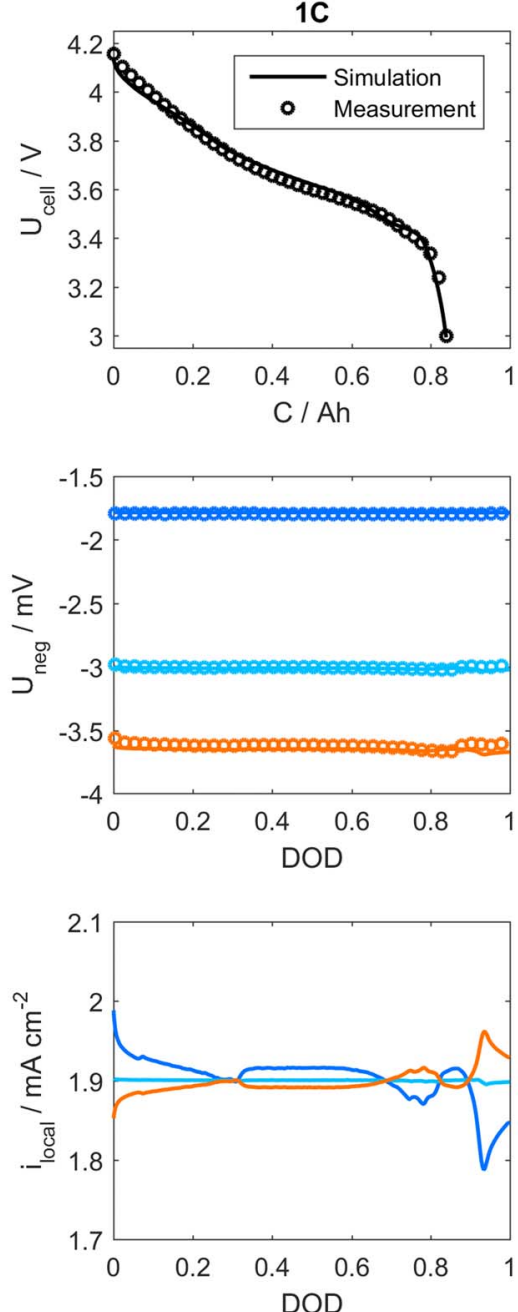
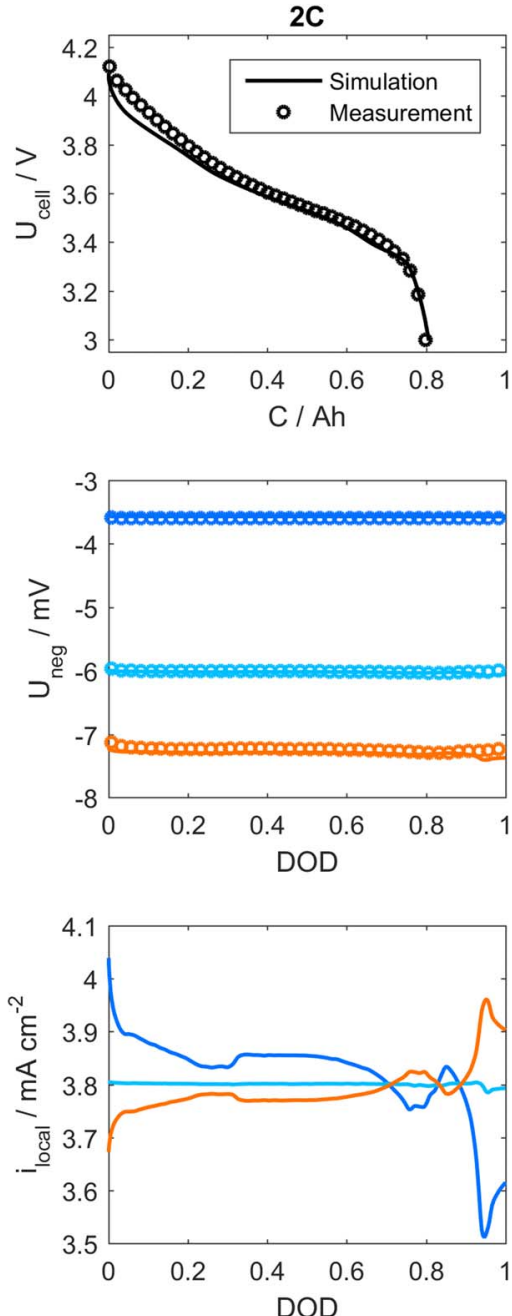

Figure 10. Simulation (solid lines) and measurement (symbols) of cell voltage (a), measured and simulated potentials at local measurement points \#01, \#05 and $\# 10$ (b), and simulated current densities at the corresponding points (c) for $0.5 \mathrm{C}, 1 \mathrm{C}$ and $2 \mathrm{C}$ at a temperature of $25^{\circ} \mathrm{C}$.

the electrical resistivity of copper, ${ }^{30}$ a temperature variation of $20 \mathrm{~K}$ corresponds to an overall decrease in conductivity of $8 \%$ and a difference of $15 \mathrm{~K}$ results in a decrease in $6 \%$, respectively. If we take the initial voltage amplitudes of $0.33 \mathrm{mV}, 0.36 \mathrm{mV}$ and $0.38 \mathrm{mV}$ from Fig. 9a as a reference for the temperatures, the difference between them corresponds quite well to the relative change in conductivity of copper:

$$
\begin{aligned}
& \frac{0.36-0.33}{0.33} \frac{\mathrm{mV}}{\mathrm{mV}}=0.091 \\
& \frac{0.38-0.36}{0.36} \frac{\mathrm{mV}}{\mathrm{mV}}=0.056
\end{aligned}
$$

That means that at a $0.1 \mathrm{C}$ discharge rate, the temperature dependent current collector resistance causes the absolute potential drop whereas other processes lead to stronger oscillations at higher temperatures. Here, we assume enhanced kinetics and mass transport to have more influence on the electrodes' sensitivity toward small potential disturbances. Since the resistivity of aluminum has nearly the same temperature dependence of $0.004 \mathrm{~K}^{-1}$, these results hold for both current collector foils.

To correlate these findings with the current rate, the same set of three temperatures was applied at $2 \mathrm{C}$ discharge rate, which is shown Fig. 9b. As stated before, the higher the rate, the less pronounced the oscillations in the voltage signal along the electrode become. The spread in between the absolute potential drop follows the same trend as for $0.1 \mathrm{C}$, namely a linear increase of potential drop depending on temperature due to the increasing current collector's resistance. Considering the initial potential values, the difference yields $7.5 \%$ between $5^{\circ} \mathrm{C}$ and $20^{\circ} \mathrm{C}$, and $3.3 \%$ between $20^{\circ} \mathrm{C}$ and $40^{\circ} \mathrm{C}$ (Fig. $9 \mathrm{~b}$ ). Both are slightly smaller than those at $0.1 \mathrm{C}$, which might be an indicator for additional effects, mainly kinetics and mass transport. That means, the potential drop does not only follow Ohm's law by temperature dependent resistivity, but corresponds to non-linearly increased kinetics within the active material as well as changed transport parameters of the electrolyte. Unfortunately, the cell's current rate is limited to $2 \mathrm{C}$ to ensure adequate life time, otherwise this relation could have been stressed in terms of higher rates. Finally, the combination of low temperatures and high C-rate seems to show the lowest oscillations without any deviations. This corresponds to the findings of Zhang et al. ${ }^{7}$ and Osswald et al., ${ }^{19}$ where the current density distribution is more uniform at lower temperatures.

Model Analysis._Current Rate Dependency.-In Fig. 10 the comparison of simulated and measured data for $0.5 \mathrm{C}, 1 \mathrm{C}$ and $2 \mathrm{C}$ at $25^{\circ} \mathrm{C}$ is shown. In general, the model is capable of representing the cell voltage at the reference tabs precisely, which is shown in the upper part (a) of Fig. 10. At a discharge rate of $0.5 \mathrm{C}$, the modeled cell potential drops to the cutoff voltage slightly earlier than in the measurement. Additionally, the simulation is not able to fit the first part of the discharge at $2 \mathrm{C}$. This combination suggests a superimposition of non-ideally suited mass transport parameters and the electrodes' OCV 
or its initial concentrations, respectively. Still, we face a limitation in terms of using measured transport parameters from the electrolyte applied to the cell. In this study, a comparable set of fitted parameters from literature ${ }^{31}$ is transferred to our cell setup, assuming sufficient representation of any concentration dependent electrolyte transport limitation. Further, although the OCV of both electrodes was measured with coin cells versus lithium, the initial stoichiometry remains a fitting parameter. Additionally, some contribution from the edge area of the electrodes ${ }^{32}$ as well as side reactions within the cell might influence this initial stoichiometry parameter. In sum, without having precise transport parameters, kinetic parameters as well as morphologic information of the electrode, an ambiguity inevitably remains. But in this case, we focus rather on the local distribution of variables such as SOC, current density and potential drop along the electrodes than on exact model parametrization. On that account, the simulation results are in sufficient accordance with the measurement and can be used as a reference for analyzing the current density distribution.

The local potentials derived from the model fit quite well to the measurement data, which can be seen in Fig. 10b. Nearly no error occurs at $0.5 \mathrm{C}$ as well as $1 \mathrm{C}$ and $2 \mathrm{C}$. This result is a distinct improvement to our previous study, ${ }^{4}$ where thermal gradients within the cell superimposed the electrochemical cell performance and larger deviations between simulation and measurement remained. With a single-layered pouch cell approach, the assumption of negligible thermal gradients simplifies the investigation of model and parameter quality. The oscillations within the local potential signal are generally represented by the model, whereas their amplitude seems to be too small, which can be seen in Fig. $10 \mathrm{~b}$ at $0.5 \mathrm{C}$ and a DOD of more than $80 \%$.

With the aid of this validated modeling approach, the simulation results from Fig. 10c give a correlation to the current densities within the electrolyte throughout the separator at the tab positions of \#01, \#05 and \#10. As expected, the current density variation increases with higher C-rates. If we take a closer look to the highest deviation between the electrode positions, which occurs toward the end of discharge, differences of up to $4 \%, 5 \%$ and $8 \%$ corresponding to $0.5 \mathrm{C}$, $1 \mathrm{C}$ and $2 \mathrm{C}$ occur. The difference between $0.5 \mathrm{C}$ and $1 \mathrm{C}$ is considerably small, following mainly the characteristic graphite potential peaks. At $2 \mathrm{C}$, the current density distribution becomes substantially more inhomogeneous, while the front part of the cell (\#01) is providing more current than the rear part (\#10) for a wide SOC range. After $70 \%$ of discharge time, this ratio gets inverted and the current in the front part decreases.

In general, a similar behavior is observable for all C-rates. At every OCV induced step in the potential curve, the current density follows accordingly. As long as the OCV is nearly constant, which accounts for graphite in its lithiation range from roughly 0.3 to 1 while excluding the phase change at about 0.5 , the current density distribution changes slightly showing nearly constant values (refer to part c in Fig. 10). During such a period the cell segments discharge unequally and their specific state of charge as well as their kinetics change unequally as well. As a consequence, the current density distribution alters significantly, when either a cell segment is facing a very low state of charge or when the OCV curve shows a considerable slope. In comparison to studies of LFP/graphite cells, ${ }^{5-7,20}$ the NMC/graphite combination provides a distinctly smaller current density spread along the electrodes. This relates to the continuously decreasing OCV of NMC, which can be approximated as nearly linear between $4.2 \mathrm{~V}$ and $3.6 \mathrm{~V}$ which results in a less pronounced inhomogeneity during discharge. In contrast to that, LFP has almost no potential variation throughout $80 \%$ of its operation range and, thus, provokes more inhomogeneity in the current density distribution along the electrodes.

Temperature Dependency.-In Fig. 11 the model quality is illustrated in terms of its temperature dependence. The measurements are compared to the respective simulations at $5^{\circ} \mathrm{C}, 25^{\circ} \mathrm{C}$ and $40^{\circ} \mathrm{C}$. The cell voltage is represented accurately by the model (a). Also, the absolute value of the local potentials and the spread between the three signals is modeled sufficiently well (b). Only the amplitude of the oscillations at the end of discharge, most pronounced at $2 \mathrm{C}$ and a DOD of $90 \%$, is not as large as monitored by the measurement. We assume that the interplay of not well-fitted parameters, such as the electrolyte's transport properties and the electrode kinetics, lead to these deviations for the oscillating behavior of the cell. Nevertheless, as stated for the C-rate dependency, the temperature influence seems to be sufficiently represented. Hence, we can rely on the investigation of current density distribution in Fig. 11c. The higher the temperature, the more inhomogeneous the current density distribution gets within the cell, whereby the difference between $25^{\circ} \mathrm{C}$ and $40^{\circ} \mathrm{C}$ is slightly smaller than the difference between $5^{\circ} \mathrm{C}$ and $25^{\circ} \mathrm{C}$. In contrast to that, the measured local potentials as illustrated in Fig. 9 show a larger amplitude in the oscillating behavior at $40^{\circ} \mathrm{C}$, which is more distinct compared to $25^{\circ} \mathrm{C}$. This cannot be represented by the model in its full spread. Though, a general statement in terms of temperature dependency of the current density distribution can be deduced. For higher cell temperatures, the inhomogeneity of the current density distribution increases, ranging from $5 \%$ at $5^{\circ} \mathrm{C}$ up to nearly $11 \%$ at $40^{\circ} \mathrm{C}$, referred to a DOD of $90 \%$ (see Fig. 11c).

Preliminary sensitivity studies revealed that the reaction rate constant and its influence on the exchange current density in the ButlerVolmer kinetics affect the amplitude of the visible oscillations in the local potential measurement (refer to Fig. 11b) as well as in the current density distribution (refer to Fig. 11c). During the measurement, the cell was kept at the listed temperatures for several weeks. Unfortunately, that led to a capacity fade superimposed onto these results. At the end of the measurements, we recognized a distinct rise of the absolute potential drop correlated to the cathode, whereas the spread in between the local potentials remained the same. Hence, we assume that additional contact resistances between the aluminum foil and the cathode coating increase and interfere our interpretation of the reaction rate constant as well as its temperature dependency. That might be the reason for the model's underestimation of the potential oscillation and the small difference of the current density variations between $25^{\circ} \mathrm{C}$ and $40^{\circ} \mathrm{C}$ (refer to Fig. 11c). Since the cell is still under operation, we can clarify that point of view as soon as we open up the cell.

SOC dependency.-In addition to the analysis of the current density distribution, the SOC distribution within the electrode can be calculated by the model. Fig. 12 shows the simulated absolute SOC deviation in percent points along the electrode for all C-rates. Generally, the deviation increases during discharge, whereby small variations occur due to the OCV characteristics of the active material, in this case mainly due to graphite. Interestingly, the inhomogeneity declines after reaching its maximum at about $70 \%$ of the discharge time. This is in correspondence with the findings of Zhang et al. ${ }^{7}$ They also observed a homogenization period at the end of the discharge, where regions far from the reference tabs deliver higher current densities. Especially at high rates, whether for discharge or charge conditions, this gives implications about the effect of a constant current protocol on electrode utilization within substantially prolonged electrodes. The maximum deviation is in the range of about $1.2 \%$ (Fig. 12c) and occurs at a DOD values of about $70 \%$. An effect of varying temperature on the SOC distribution is visible, but is rather small at lower C-rates. In contrast to that, a clear dependency can be seen at $2 \mathrm{C}$. At $40^{\circ} \mathrm{C}$ a deviation of about $1.3 \%$ occurs, whereas at $5^{\circ} \mathrm{C}$ a substantially smaller value of $0.7 \%$ appears. Further, the deviation remains at a value of about $0.5 \%$ for all temperatures at the end of the discharge. Contrarily, at $5^{\circ} \mathrm{C}$ the cell gets nearly homogenized at the end of discharge. That means, in combination with higher current rates, the temperature has a major effect on the cell inhomogeneity and a uniform active material utilization. Especially for interrupted discharge profiles at a DOD of $70 \%$, the effect is most pronounced. If normalized to its electrode length, a maximum deviation of about 0.6 percent can be identified for the distance of $46 \mathrm{~cm}$ at $1 \mathrm{C}$ and $25^{\circ} \mathrm{C}$, which corresponds to 0.013 percent points per $\mathrm{cm}$. In our ongoing study, we are investigating the influence of a thermal gradient on this result. It can be assumed that a higher temperature at the reference tabs will cause an even more inhomogeneous SOC distribution throughout the electrode. 
$5^{\circ} \mathrm{C}$
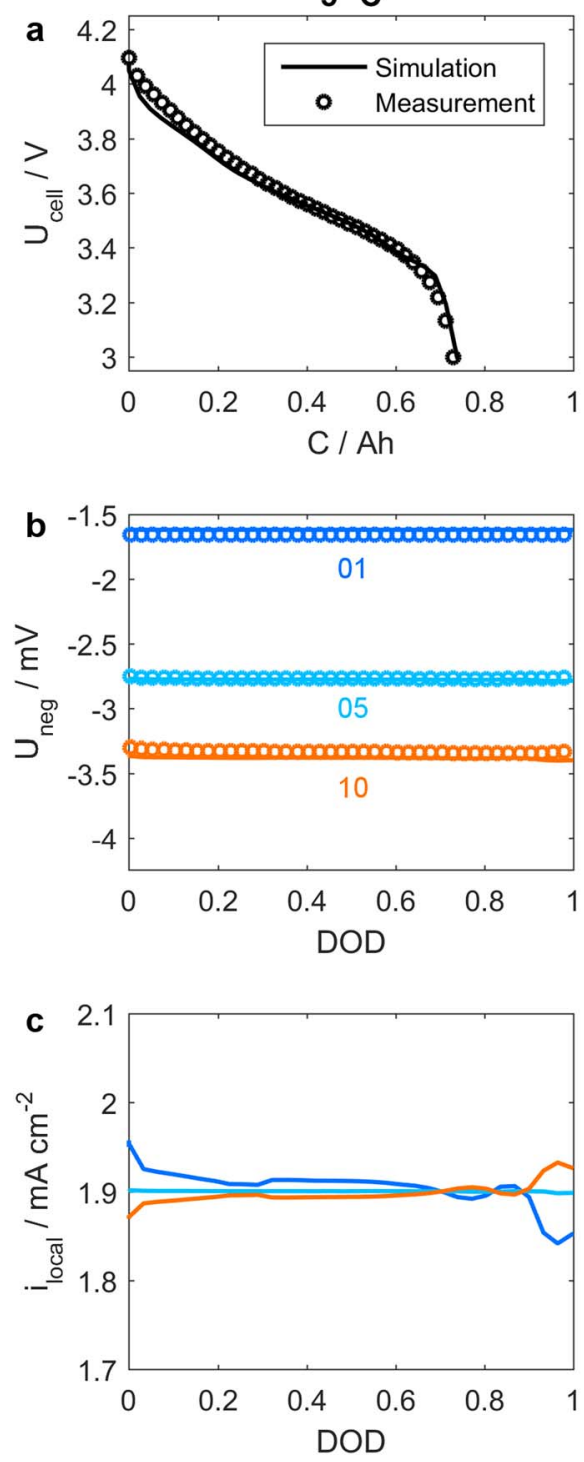

$25^{\circ} \mathrm{C}$
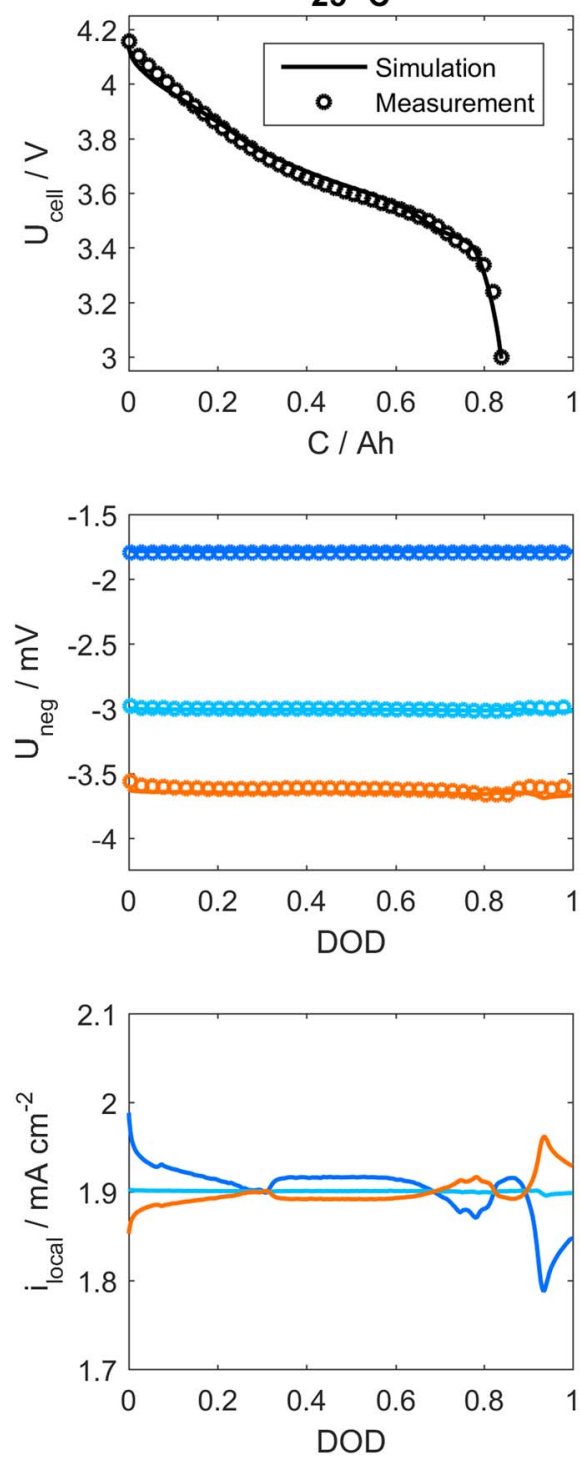

$40^{\circ} \mathrm{C}$
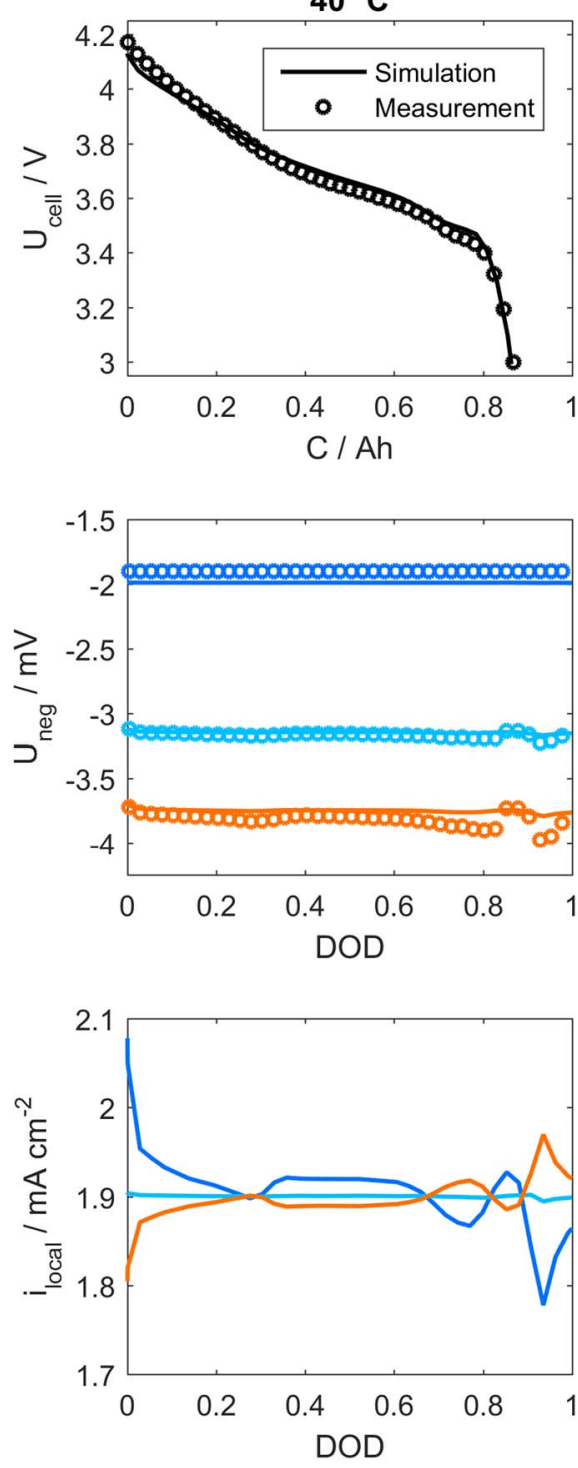

Figure 11. Simulation (solid lines) and measurement (symbols) of cell voltage (a), measured and simulated potentials at local measurement points \#01, \#05 and $\# 10$ (b), and simulated current densities at the corresponding points (c) for $1 \mathrm{C}$ at temperatures of $5^{\circ} \mathrm{C}, 25^{\circ} \mathrm{C}$ and $40^{\circ} \mathrm{C}$.

It is worth stating here that the current collector foils used in our cell are relatively thick and are usually applied to double coated electrode sheets. Thinner current collector foils were not available at the time. This implies that the potential drop along the electrodes will more or less double throughout the discharge procedure which involves a more inhomogeneous utilization of the electrodes. It can be therefore assumed that the SOC variation will also increase when a double coated electrode or half the current collector thickness is utilized.

\section{Conclusions}

In this study, the method of using local potentials as internal state variables for gathering insights into the current density and SOC distribution within lithium-ion batteries was applied to a prototype $\mathrm{NMC} /$ graphite pouch cell. With a size of $500 \times 100 \mathrm{~mm}^{2}$ and 44 tabs, the cell allows for a detailed differential voltage measurement along the electrodes during common operation scenarios. Due to its singlelayered cell design, the heat capacity is low in contrast to the heat exchange via the cell's surface and tabs, so that a constant temperature is maintained even at high discharge rates of up to $2 \mathrm{C}$. We performed an analysis for four discharge rates and three temperatures, applying a standard tab configuration to the pouch cell. Additionally, our multidimensional modeling framework was used for simulating the internal current density and SOC distribution, after being validated by means of the local potential measurements along the electrode. For parametrization, most of the geometric cell values are measured, whereas the electrolyte properties and electrode kinetic parameters are taken from literature and fitted depending on C-rates and temperature. The study illustrates that the current density peaks are following the electrodes' characteristics of the $\mathrm{OCV}$, clearly visible at lower C-rates. As soon as the C-rate is large enough, the peaks vanish and the local potential is predominantly shaped by the ohmic drop along the current collector foil. Extended by the model results, our study further reveals that temperature has a positively coupled effect on the cell inhomogeneity during discharge. This can be related to enhanced kinetics and mass transport within the electrode and separator domain as well as an increased current collector foil resistance. The deviation in SOC was about 0.013 percent per $\mathrm{cm}$ at a $1 \mathrm{C}$ discharge at $25^{\circ} \mathrm{C}$ and $70 \%$ DOD, taken from the maximum difference between the first tab (\#01) and the last tab (\#10). Generally, the SOC distribution is most inhomogeneous at a DOD of $70 \%$ and equalizes at the end of the discharge, where only a small deviation remains. Our results were compared to preliminary studies which used modified LFP/graphite cells. Further 

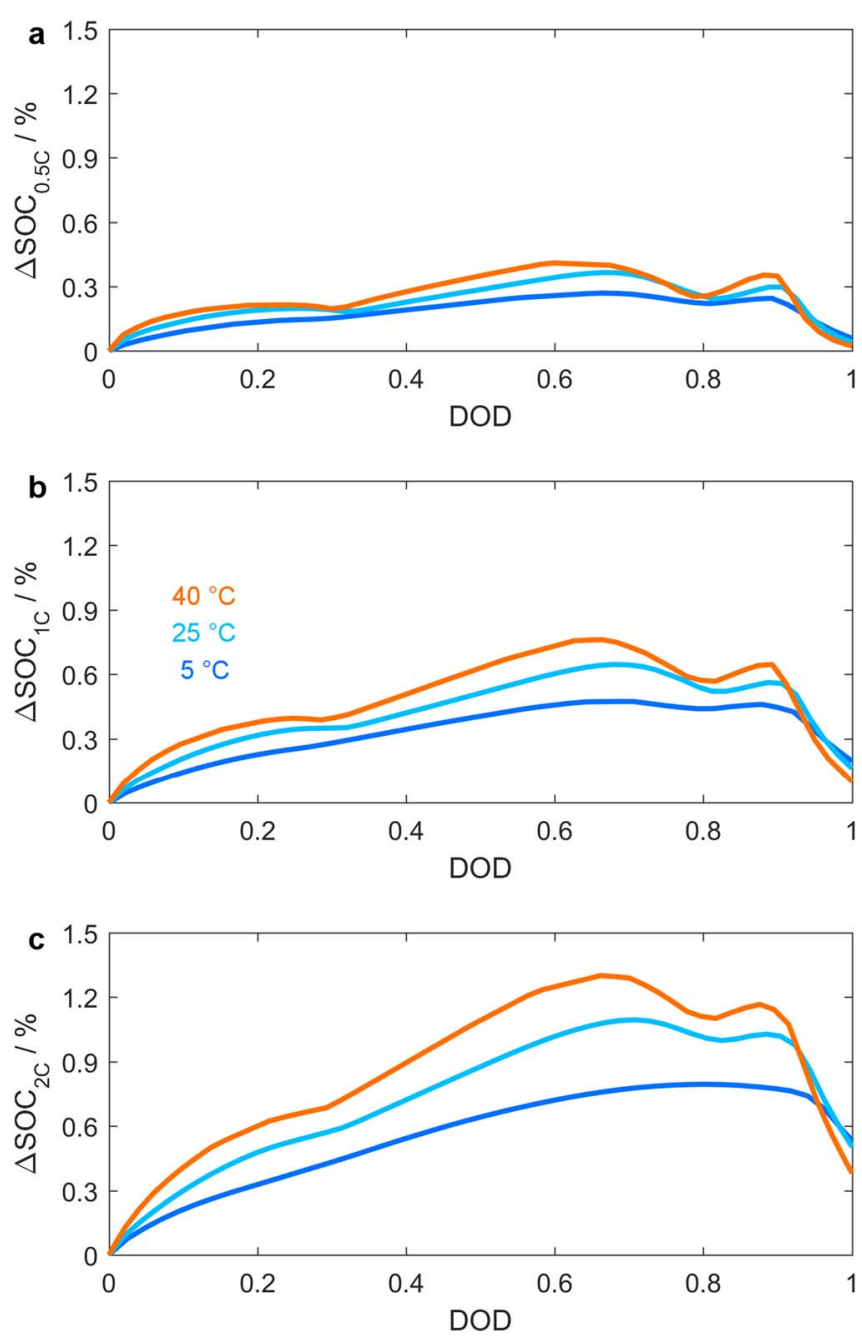

Figure 12. Simulated deviation within state of charge along the electrode for $0.5 \mathrm{C}(\mathrm{a}), 1 \mathrm{C} \mathrm{(b)}$ and $2 \mathrm{C}$ (c) at $25^{\circ} \mathrm{C}$. The deviation corresponds to the difference in SOC within the anode, averaged over its layer thickness, between tab \#01 and tab \#10.

studies will focus on more precise electrochemical parameter determination in order to clarify their sensitivity regarding current density and SOC distribution. Additionally, subjecting the cell to defined thermal gradients to influence the SOC inhomogeneity should provide further insights.

\section{Acknowledgment}

The presented work is supported by the Bavarian Ministry of Economic Affairs and Media, Energy and Technology under the auspices of the EEBatt project.

\section{References}

1. B. Scrosati and J. Garche, "Lithium batteries: Status, prospects and future," Journal of Power Sources, 195(9), 2419 (2010).

2. J. M. Tarascon and M. Armand, "Issues and challenges facing rechargeable lithium batteries," Nature, 414(6861), 359 (2001).

3. P. J. Osswald, S. V. Erhard, A. Noel, P. Keil, F. M. Kindermann, H. Hoster, and A. Jossen, "Current density distribution in cylindrical Li-Ion cells during impedance measurements," Journal of Power Sources, 314, 93 (2016).

4. S. V. Erhard, P. J. Osswald, J. Wilhelm, A. Rheinfeld, S. Kosch, and A. Jossen, "Simulation and Measurement of Local Potentials of Modified Commercial Cylindrical Cells: II: Multi-Dimensional Modeling and Validation," Journal of The Electrochemical Society, 162(14), A2707 (2015).

5. P. J. Osswald, S. V. Erhard, J. Wilhelm, H. E. Hoster, and A. Jossen, "Simulation and Measurement of Local Potentials of Modified Commercial Cylindrical Cells: I. Cell
Preparation and Measurements," Journal of The Electrochemical Society, 162(10), A2099 (2015)

6. G. Zhang, C. E. Shaffer, C.-Y. Wang, and C. D. Rahn, "Effects of Non-Uniform Current Distribution on Energy Density of Li-Ion Cells," Journal of The Electrochemical Society, 160(11), A2299 (2013)

7. G. Zhang, C. E. Shaffer, C.-Y. Wang, and C. D. Rahn, "In-Situ Measurement of Current Distribution in a Li-Ion Cell," Journal of The Electrochemical Society, 160(4), A610 (2013).

8. G.-H. Kim, K. Smith, K.-J. Lee, S. Santhanagopalan, and A. Pesaran, "Multi-Domain Modeling of Lithium-Ion Batteries Encompassing Multi-Physics in Varied Length Scales," J. Electrochem. Soc, 158(8), A955 (2011).

9. K.-J. Lee, K. Smith, A. Pesaran, and G.-H. Kim, "Three dimensional thermal-, electrical-, and electrochemical-coupled model for cylindrical wound large format lithium-ion batteries," Journal of Power Sources, 241(0), 20 (2013).

10. Y. Ye, L. H. Saw, Y. Shi, K. Somasundaram, and A. A. Tay, "Effect of thermal contact resistances on fast charging of large format lithium ion batteries," Electrochimica Acta, 134, 327 (2014).

11. I. A. Hunt, Y. Zhao, Y. Patel, and J. Offer, "Surface Cooling Causes Accelerated Degradation Compared to Tab Cooling for Lithium-Ion Pouch Cells," Journal of The Electrochemical Society, 163(9), A1846 (2016).

12. Y. Merla, B. Wu, V. Yufit, N. P. Brandon, R. F. Martinez-Botas, and G. J. Offer, "Novel application of differential thermal voltammetry as an in-depth state-of-health diagnosis method for lithium-ion batteries," Journal of Power Sources, 307, 308 (2016).

13. D. A. H. McCleary, J.P. Meyers, and B. Kim, "Three-Dimensional Modeling of Electrochemical Performance and Heat Generation of Spirally and Prismatically Wound Lithium-Ion Batteries," Journal of The Electrochemical Society, 160(11), A1931 (2013)

14. R. E. Gerver and J. P. Meyers, "Three-Dimensional Modeling of Electrochemical Performance and Heat Generation of Lithium-Ion Batteries in Tabbed Planar Configurations," J. Electrochem. Soc, 158(7), A835 (2011).

15. K. H. Kwon, C. B. Shin, T. H. Kang, and C.-S. Kim, "A two-dimensional modeling of a lithium-polymer battery," Journal of Power Sources, 163(1), 151 (2006).

16. U. S. Kim, J. Yi, C. B. Shin, T. Han, and S. Park, "Modeling the Thermal Behaviors of a Lithium-Ion Battery during Constant-Power Discharge and Charge Operations," Journal of The Electrochemical Society, 160(6), A990 (2013).

17. S. Klink, W. Schuhmann, and F. La Mantia, "Vertical distribution of overpotentials and irreversible charge losses in lithium ion battery electrodes," ChemSusChem, 7(8), 2159 (2014).

18. S.-H. Ng, F. La Mantia, and P. Novak, "A multiple working electrode for electrochemical cells: a tool for current density distribution studies," Angewandte Chemie (International ed. in English), 48(3), 528 (2009).

19. P. J. Osswald, S. V. Erhard, A. Rheinfeld, B. Rieger, H. E. Hoster, and A. Jossen, "Temperature dependency of state of charge inhomogeneities and their equalization in cylindrical lithium-ion cells," Journal of Power Sources, 329, 546 (2016).

20. T. Waldmann, G. Geramifard, and M. Wohlfahrt-Mehrens, "Influence of current collecting tab design on thermal and electrochemical performance of cylindrical Lithium-ion cells during high current discharge," Journal of Energy Storage, 5, 163 (2015).

21. T. Waldmann, G. Bisle, B.-I. Hogg, S. Stumpp, M. A. Danzer, M. Kasper, P. Axmann, and M. Wohlfahrt-Mehrens, "Influence of Cell Design on Temperatures and Temperature Gradients in Lithium-Ion Cells: An In Operando Study," Journal of The Electrochemical Society, 162(6), A921 (2015).

22. T. Waldmann and M. Wohlfahrt-Mehrens, "In-Operando Measurement of Temperature Gradients in Cylindrical Lithium-Ion Cells during High-Current Discharge," ECS Electrochemistry Letters, 4(1), A1 (2015).

23. Y.-S. Chen, K.-H. Chang, C.-C. Hu, and T.-T. Cheng, "Performance comparisons and resistance modeling for multi-segment electrode designs of power-oriented lithiumion batteries," Electrochimica Acta, 55(22), 6433 (2010).

24. F. M. Kindermann, A. Noel, S. V. Erhard, and A. Jossen, "Long-term equalization effects in Li-ion batteries due to local state of charge inhomogeneities and their impact on impedance measurements," Electrochimica Acta, 185, 107 (2015).

25. A. Barai, G. H. Chouchelamane, Y. Guo, A. McGordon, and P. Jennings, "A study on the impact of lithium-ion cell relaxation on electrochemical impedance spectroscopy," Journal of Power Sources, 280, 74 (2015).

26. Analog Devices Inc., Ultralow noise 24-bit sigma-delta analog-digital converter (AD7193), available at http://www.analog.com/en/products/analog-to-digitalconverters/ad-converters/ad7193.html.

27. M. Doyle, T. F. Fuller, and J. Newman, "Modeling of Galvanostatic Charge and Discharge of the Lithium/Polymer/Insertion Cell," J. Electrochem. Soc, 140(6), 1526 (1993).

28. C. M. Doyle, Design and Simulation of Lithium Rechargeable Batteries. Ph. D. Thesis, University of California, 1995.

29. T. F. Fuller, M. Doyle, and J. Newman, "Simulation and Optimization of the Dual Lithium Ion Insertion Cell," Journal of The Electrochemical Society, 141(1), 1 (1994).

30. D. R. Lide (Ed.), CRC Handbook of chemistry and physics: 2005-2006 a readyreference book of chemical and physical data, 86th ed., CRC Press; Taylor \& Francis Group, Boca Raton, New York, Washington, 2005-2006.

31. L. O. Valoen and J. N. Reimers, "Transport Properties of $\mathrm{LiPF}_{6}-$ Based Li-Ion Battery Electrolytes," J. Electrochem. Soc, 152(5), A882 (2005).

32. B. Gyenes, D. A. Stevens, V. L. Chevrier, and J. R. Dahn, "Understanding Anomalous Behavior in Coulombic Efficiency Measurements on Li-Ion Batteries,"Journal of The Electrochemical Society, 162(3), A278 (2015).

33. J. Landesfeind, J. Hattendorff, A. Ehrl, W. A. Wall, and H. A. Gasteiger, "Tortuosity Determination of Battery Electrodes and Separators by Impedance Spectroscopy," $J$. Electrochem. Soc., 163(7), A1373 (2016). 